\title{
Dynamic Simulation of a Prototype Race Car Driven by Series Wound DC Motor in Matlab- Simulink
}

\author{
Attila Szántó, Sándor Hajdu, Gusztáv Áron Sziki \\ University of Debrecen, Doctoral School of Informatics, Kassai út 26, 4028 \\ Debrecen, Hungary, szanto.attila@zimbra.inf.unideb.hu \\ University of Debrecen, Faculty of Engineering, Ótemetú u. 2-4, 4028 Debrecen, \\ Hungary, hajdusandor@eng.unideb.hu, szikig@eng.unideb.hu
}

\begin{abstract}
In the last decade student teams at the Faculty of Engineering of the University of Debrecen have designed and constructed several race cars with alternative (electric or pneumatic) drives and took part and achieved successes in domestic and international competitions. For more successful racing a simulation program has been developed in Matlab for the calculation of the vehicle dynamic functions of the cars from their technical data. Currently, it has become a prerequisite of successful racing because of the large number of the possible values of technical data we can select the optimal ones by applying the above program combined with an optimizing procedure. The detailed description of the developed dynamic model and simulation program, together with the vehicle dynamics functions generated by the program are presented here. The description of the optimizing procedure will be presented elsewhere.
\end{abstract}

Keywords: dynamics modelling; simulation; race car; series DC motor; Matlab

\section{Introduction}

The Faculty of Engineering, University of Debrecen (FEUD) has years of experience in the designing, development, and construction of vehicles with alternative (electric or pneumatic) drives. As a part of the above activity, student teams at our faculty have designed and constructed several alternative driven race cars in the last decade and took part and achieved successes in domestic and international competitions. One of the above-mentioned competitions is the MVM Race which is sponsored and organized by the Hungarian Electrical Works Ltd (Magyar Villamos Mủvek) in Budapest from 2014, annually. With an electric driven race car - that was designed and constructed by the Department of Mechanical Engineering of FEUD - we scored first and second place in the above race in 2014 and 2015 respectively. 
With the aim of more conscious design and development, thus more effective racing, we have realised a simulation program in Matlab-Simulink for the calculation of the vehicle dynamic functions (acceleration-, velocity-, and covered distance-time functions) of a car from its technical data. The above technical data have to be measured or sometimes they can be found in the specification of a given vehicle component $[1,2,3]$. Applying the above program, together with an optimizing procedure, the optimal values of technical data - with which the best performance can be achieved (e.g. a given distance can be covered in the shortest possible time) - can be determined. For example, determining the optimal gear ratio in the chain drive is of key importance to reach the above aim.

It was important to develop a simulation program with modular structure, so that the different structural units of the car (motor, powertrain, front and back wheels, vehicle body) can be modelled and simulated separately. It was important because we design and construct vehicles with very different vehicle components (e.g. the motor can be pneumatic, electric, or combustion type, and the power train can also be very different). Restructuring the whole program when, e.g. a new type of motor is applied would be a tremendous amount of work, thus we wanted to avoid this situation.

In Section 2 a detailed technical description of the car - which won the first and second place in the MVM race in 2014 and 2015 - is given, while in Section 3 the developed dynamic model for the same car is presented. In section 4 the latest version of our simulation program - which is based on the model in Section 3 - is presented. Finally, in Section 5 the dynamics functions - generated by the simulation program for the modelled car - are presented.

\section{The Race Car}

The race car was designed considering the rules of MVM competition (prototype category), and it raced first in 2014. The vehicle has a welded frame structure, which is made up of aluminium hollow profiles and tubes (Figure 1) [4].

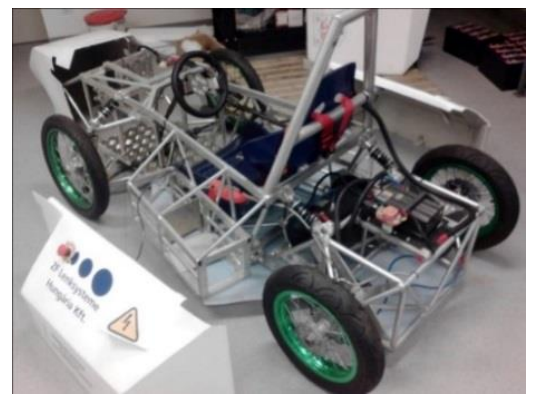

Figure 1

The race car without housing and batteries 
The car has a double-wishbone front suspension, while the rear part of the vehicle is suspended independently. This part involves the complete drive-train (Figures 2 and 3) with the electric motor, motor control unit and chain drive, and also the rear wheels. The frame structure also contains battery holders at both sides of the pilot and a safety rollover hoop as well. The vehicle is driven by a series wound DC motor. The motor (1) is connected to the rear shaft (5) through a chain-drive (2, 3, 4). Bevel roller bearings (6) are applied to support the rear shafts. The wheels (8) are connected to the rear shaft rigidly. For effective braking, a divided brake system with four brake discs (7) is applied. The mass of the car - without the driver - is $176.2 \mathrm{~kg}[4]$.

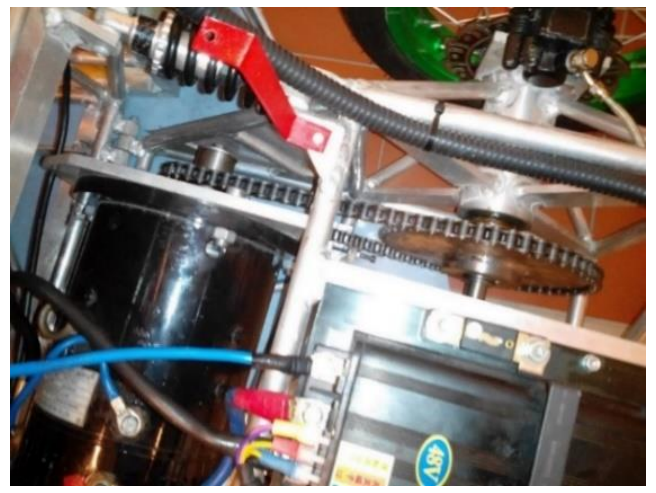

Figure 2

The drive-train of the car

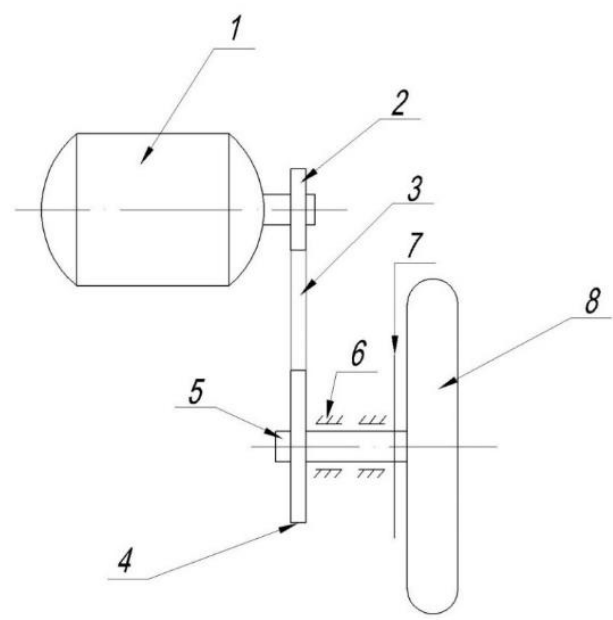

Figure 3

Schematic drawing of the drive-train 
The type and technical data of the applied electric motor are summarized in Table 1 :

Table 1

Type and technical data of the applied electric motor

\begin{tabular}{|c|c|c|c|c|c|c|}
\hline Type & $\begin{array}{c}\text { Nominal } \\
\text { voltage } \\
{[\mathrm{V}]}\end{array}$ & $\begin{array}{c}\text { Nominal } \\
\text { power } \\
{[\mathrm{kW}]}\end{array}$ & $\begin{array}{c}\text { Nominal } \\
\text { current } \\
\text { intensity } \\
{[\mathrm{A}]}\end{array}$ & $\begin{array}{c}\text { Nominal } \\
\text { speed } \\
{[1 / \mathrm{min}]}\end{array}$ & $\begin{array}{c}\text { Nominal } \\
\text { torque } \\
{[\mathrm{Nm}]}\end{array}$ & $\begin{array}{c}\text { Mass } \\
{[\mathrm{kg}]}\end{array}$ \\
\hline DC/T4-48 & 48 & 4 & 104 & 2800 & 14,7 & 28 \\
\hline
\end{tabular}

\section{The Vehicle Dynamics Model}

In our model the car is divided into four structural units (Figure 4).
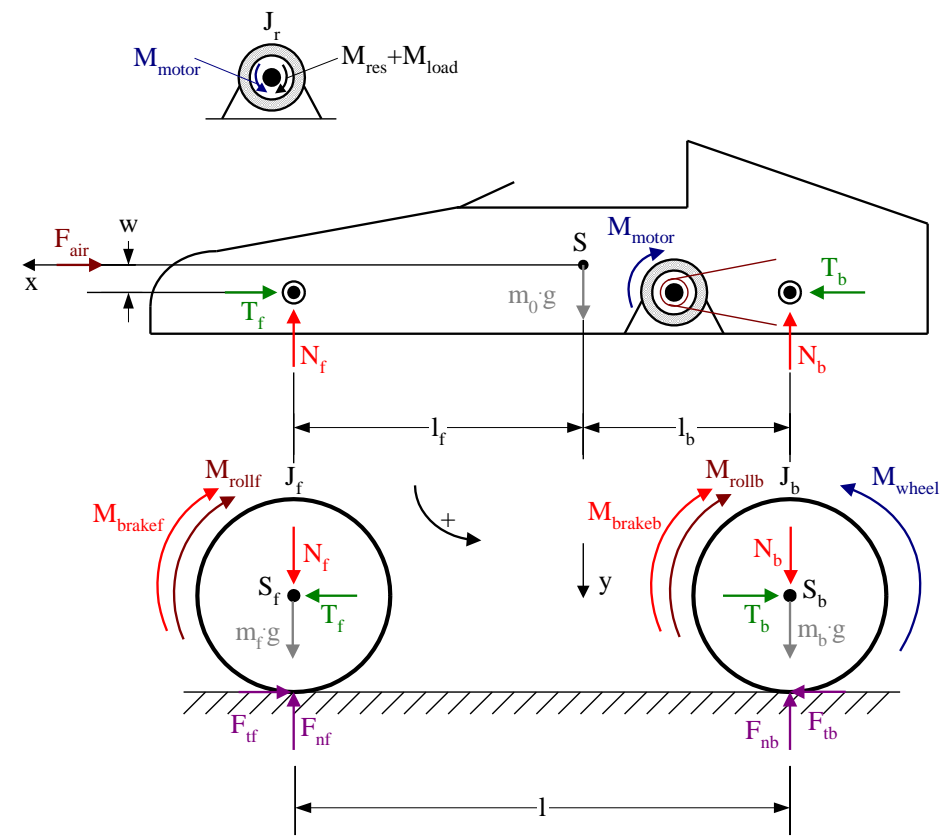

Figure 4

The developed dynamic model for the car together with the forces and torques acting on its different structural units

These units are:

1) The driven back wheels with the rotating machine parts connected to them; 
2) The freely rotating front wheels with the rotating machine parts connected to them;

3) The body of the car including the strator of the electric motor;

4) The rotor of the electric motor [4]

In the model dynamic equations are written for the above construction parts taking into consideration the different external and internal forces and moments acting on them on the basis of Newton's laws. Thus, from the above equations, we can calculate not only the external forces and moments but also the internal ones (e.g. the loads on the front and back shafts).

In our model we applied the following assumptions:

- The mass distribution of the car is symmetric to the xy plane in Figure 4. (It was checked with measurement and it is valid with a good approximation.)

- The vehicle is regarded as a rigid system. (This assumption is valid since the stiffnesses of the front and back suspensions are high, and the race track has a flat and smooth surface)

- The resultant of the air resistance force goes through the centre of mass of the vehicle and it is parallel to the vehicle's velocity.

In references [5, 6, 7] other examples for longitudinal vehicle modells are presented.

\subsection{The Model of the Electric Motor. Dynamic and Electromagnetic Equations}

For the description of the series wound DC motor we applied the following model:

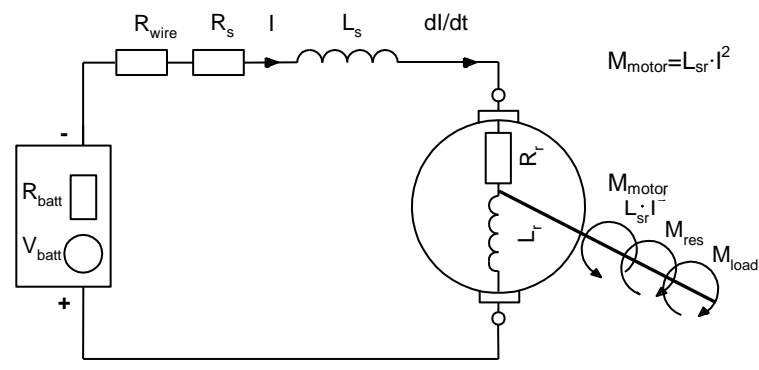

Figure 5

The applied model for the simulation of the series wound DC motor 
With the aim of describing the motion of the different structural units of the car (Figure 4) quantitatively, we established dynamics equations taking into account all the external and internal (between the different units) forces and torques.

On the basis of Figure 4 and 5 the dynamic and electromagnetic equations for the different structural units are:

Equations for the freely rotating front wheels with the rotating machine parts connected to them:

$$
\begin{gathered}
\text { I. } \sum_{i} \mathrm{~F}_{\mathrm{ix}}=\mathrm{T}_{\mathrm{f}}-\mathrm{F}_{\mathrm{tf}}=\mathrm{m}_{\mathrm{f}} \cdot \mathrm{a}_{\mathrm{s}} \rightarrow \mathrm{T}_{\mathrm{f}}=\mathrm{m}_{\mathrm{f}} \cdot \mathrm{a}_{\mathrm{s}}+\mathrm{F}_{\mathrm{tf}} \\
\text { II. } \sum_{i} \mathrm{~F}_{\mathrm{iy}}=-\mathrm{F}_{\mathrm{nf}}+\mathrm{N}_{\mathrm{f}}+\mathrm{m}_{\mathrm{f}} \cdot \mathrm{g}=0 \\
\text { III. } \sum_{i} \mathrm{M}_{\mathrm{i}\left(\mathrm{S}_{\mathrm{f}}\right)}=-\mathrm{M}_{\text {rollf }}+\mathrm{F}_{\mathrm{tf}} \cdot \mathrm{R}-\mathrm{M}_{\text {brakef }}=\mathrm{J}_{\mathrm{f}} \cdot \varepsilon_{\mathrm{f}}
\end{gathered}
$$

Equations for the driven back wheels with the rotating machine parts connected to them:

$$
\begin{gathered}
\text { IV. } \sum_{i} \mathrm{~F}_{\mathrm{ix}}=\mathrm{F}_{\mathrm{tb}}-\mathrm{T}_{\mathrm{b}}=\mathrm{m}_{\mathrm{b}} \cdot \mathrm{a}_{\mathrm{s}} \rightarrow \mathrm{T}_{b}=-\mathrm{m}_{\mathrm{b}} \cdot \mathrm{a}_{\mathrm{s}}+\mathrm{F}_{\mathrm{tb}} \\
\text { V. } \sum_{i} \mathrm{~F}_{\mathrm{iy}}=-\mathrm{F}_{\mathrm{nb}}+\mathrm{N}_{\mathrm{b}}+\mathrm{m}_{\mathrm{b}} \cdot \mathrm{g}=0 \\
\text { VI. } \sum_{i} \mathrm{M}_{\mathrm{i}\left(\mathrm{S}_{\mathrm{b}}\right)}=-\mathrm{M}_{\text {rollb }}-\mathrm{M}_{\text {brakeb }}-\mathrm{F}_{\mathrm{tb}} \cdot \mathrm{R}+\mathrm{M}_{\text {wheel }}=\mathrm{J}_{\mathrm{b}} \cdot \varepsilon_{\mathrm{b}}
\end{gathered}
$$

Equations for the vehicle body:

$$
\begin{gathered}
\text { VII. } \sum_{i} \mathrm{~F}_{\mathrm{ix}}=\mathrm{T}_{\mathrm{b}}-\mathrm{T}_{\mathrm{f}}-\mathrm{F}_{\mathrm{air}}=\mathrm{m}_{0} \cdot \mathrm{a}_{\mathrm{s}} \\
\text { VIII. } \sum_{i} \mathrm{~F}_{\mathrm{iy}}=-\mathrm{N}_{\mathrm{f}}-\mathrm{N}_{\mathrm{b}}+\mathrm{m}_{0} \cdot \mathrm{g}=0 \\
\text { IX. } \sum_{i} \mathrm{M}_{\mathrm{i}(\mathrm{S})}=-\mathrm{M}_{\text {motor }}-\mathrm{N}_{\mathrm{f}} \cdot \mathrm{l}_{\mathrm{f}}+\mathrm{N}_{\mathrm{b}} \cdot \mathrm{l}_{\mathrm{b}}+\mathrm{T}_{\mathrm{f}} \cdot \mathrm{w}-\mathrm{T}_{\mathrm{b}} \cdot \mathrm{w}=0
\end{gathered}
$$

Equation for the rotor of the electric motor (only for rotational motion):

$$
\mathrm{X} . \quad \overbrace{\mathrm{L}_{\mathrm{sr}} \cdot \mathrm{I}^{2}}^{\mathrm{M}_{\text {motor }}}-\mathrm{M}_{\text {res }}-\mathrm{M}_{\text {load }}=\mathrm{J}_{\mathrm{r}} \cdot \varepsilon_{\text {mot }}=\mathrm{J}_{\mathrm{r}} \cdot \mathrm{i}_{12} \cdot \varepsilon_{\mathrm{b}} \quad\left(\varepsilon_{\mathrm{b}}=\varepsilon_{\text {mot }} \cdot \frac{1}{\mathrm{i}_{12}}\right)
$$

Connection between the driving torque on the back shaft $\left(\mathrm{M}_{\text {wheel }}\right)$ and the loading torque on the electric motor: 


$$
\text { XI. } \quad M_{\text {wheel }}=-\eta \cdot i_{12} \cdot M_{\text {load }} \quad\left(i_{12}=\frac{z_{2}}{z_{1}}\right)
$$

Electromagnetic equation for the electric motor:

$$
\text { XII. } \mathrm{V}_{\text {batt }}\left(\mathrm{R}_{\mathrm{s}}+\mathrm{R}_{\mathrm{r}}+\mathrm{R}_{\text {batt }}+\mathrm{R}_{\text {wire }}\right) \cdot \mathrm{I}-\left(\mathrm{L}_{\mathrm{s}}(\mathrm{I})+\mathrm{L}_{\mathrm{r}}(\mathrm{I})\right) \cdot \frac{\mathrm{dI}}{\mathrm{dt}}-\mathrm{L}_{\mathrm{sr}}(\mathrm{I}) \cdot \omega \cdot \mathrm{I}=0
$$

The parameters in the above equations are:

$M_{\text {wheel }}$ : magnitude of the torque exerted by the chain drive on the back shaft

$\mathrm{M}_{\text {motor }}$ : magnitude of the torque exerted by the strator of the motor on its rortor

$\mathrm{M}_{\text {rollf, }} \mathrm{M}_{\text {rollb}}$ : magnitude of the rolling resistance torque on the front and back wheels

$\mathrm{F}_{\text {air }}$ : resultant of air resistance force

$\mathrm{F}_{\mathrm{tf}}, \mathrm{F}_{\mathrm{tb}}$ : magnitude of the force exerted by the road on the front and back wheels in tangential direction

$\mathrm{F}_{\mathrm{nf}}, \mathrm{F}_{\mathrm{nb}}$ : magnitude of the force exerted by the road on the front and back wheels in normal direction

$\mathrm{T}_{\mathrm{f}}, \mathrm{T}_{\mathrm{b}}$ : load on the front and back shaft in tangential direction

$\mathrm{N}_{\mathrm{f}}, \mathrm{N}_{\mathrm{b}}$ : load on the front and back shaft in normal direction

$S_{\mathrm{f}}, \mathrm{S}_{\mathrm{b}}, \mathrm{S}$ : centre or gravity of the front and back wheels and the whole vehicle

$\mathrm{M}_{\text {brakef }}, \mathrm{M}_{\text {brakeb }}$ : braking torques on the front and back wheels

$\eta$ : efficiency of the chain drive

$\mathrm{z}_{1}, \mathrm{z}_{2}$ : number of teeth on the driver and driven sprockets

$\mathrm{i}_{12}$ : gear ratio in the chain drive

$\varepsilon_{\text {mot }}$ : angular acceleration of the rotor of the motor

$\varepsilon_{\mathrm{b}}$ : angular acceleration of the driven back wheels

$\mathrm{R}_{\text {batt }}$ : the battery's internal resistance

$\mathrm{V}_{\text {batt: }}$ the battery's electromotive force

$\mathrm{R}_{\text {wire: }}$ resultant resistance of the wires connecting the battery to the motor

$R_{s}$, $R_{r}$ : electric resistances of the rotor and stator windings

I: the intensity of current flowing through the motor

$\mathrm{L}_{s}$ : self dynamic inductance of the stator winding

$\mathrm{L}_{\mathrm{r}}$ : self dynamic inductance of the rotor winding 
$\mathrm{L}_{\mathrm{sr}}$ : mutual dynamic inductance

$\mathrm{M}_{\text {res: }}$ : sum of the bearing resistance and brush friction torques on the rotor of the motor

$\mathrm{M}_{\text {load }}$ : loading torque on the rotor of the motor [8]

1: distance between the front and back shafts in tangential direction

$1_{\mathrm{f}}, \mathrm{l}_{\mathrm{b}}$ : distance of the centre of mass of the vehicle from the front and back shaft respectively in tangential direction

w: distance of the centre of mass of the vehicle from the front and back shafts in normal direction

$\mathrm{m}_{0}$ : mass of the vehicle body including the driver

$\mathrm{m}_{\mathrm{f}}, \mathrm{m}_{\mathrm{b}}$ : mass of the front and back wheels with the rotating machine parts connected to them

$\mathrm{J}_{\mathrm{f}}, \mathrm{J}_{\mathrm{b}}$ : moment of inertia of the front and back wheels with the rotating machine parts connected to them

$\mathrm{J}_{\mathrm{r}}$ : moment of inertia of the rotor of the motor

$\mathrm{R}$ : effective wheel radius

The electromagnetic and dynamic characteristic of the applied electric motor $\left(R_{\text {batt }}, V_{\text {batt }}, R_{\text {wire, }}, R_{s}, R_{r}, L_{s}, L_{r}, L_{s r}, M_{r e s}, J_{r}\right.$ ) were measured previously by the authors [9]. Some of the other vehicle parameters ( $M_{\text {rollf, }} M_{\text {rollb }}, l, l_{f}, l_{b}, w, m_{0}, m_{f}$, $\mathrm{m}_{\mathrm{b}}, \mathrm{J}_{\mathrm{f}}, \mathrm{J}_{\mathrm{b}}, \mathrm{R}$ ) were also measured, while the remaining ones were approximated on the basis of literature data.

\subsection{Additional Formulas}

Tyre slip:

During acceleration the longitudinal slip of the front and back tyres is calculated as:

$$
\operatorname{slip}=\frac{\omega \cdot R-v_{s}}{\omega \cdot R} \cdot 100 \%
$$

while during deceleration,

$$
\text { slip }=\frac{\omega \cdot R-v_{s}}{v_{s}} \cdot 100 \%
$$

where $\omega$ is the wheel's angular speed, $R$ is the effective wheel radius and $v_{s}$ is the speed of the vehicle. [4]

Coefficient of friction: 
The coefficient of friction (the ratio of the tangential and normal force exerted by the road on the tyres) was calculated by the Pacejka formula $[2,3,4,9]$ :

$$
\frac{F_{t b}}{F_{n b}}=\mu=c_{1} \cdot \sin \left(c_{2} \cdot \operatorname{atan}\left(c_{3} \cdot \operatorname{slip}-c_{4} \cdot\left(c_{3} \cdot \operatorname{slip}-\operatorname{atan}\left(c_{3} \cdot \operatorname{slip}\right)\right)\right)\right)
$$

Where $c_{1}, c_{2}, c_{3}$ and $c_{4}$ are constants based on the tire experimental data. The constants above are referred to as the stiffness, shape, peak and curvature coefficients respectively. [1,7]

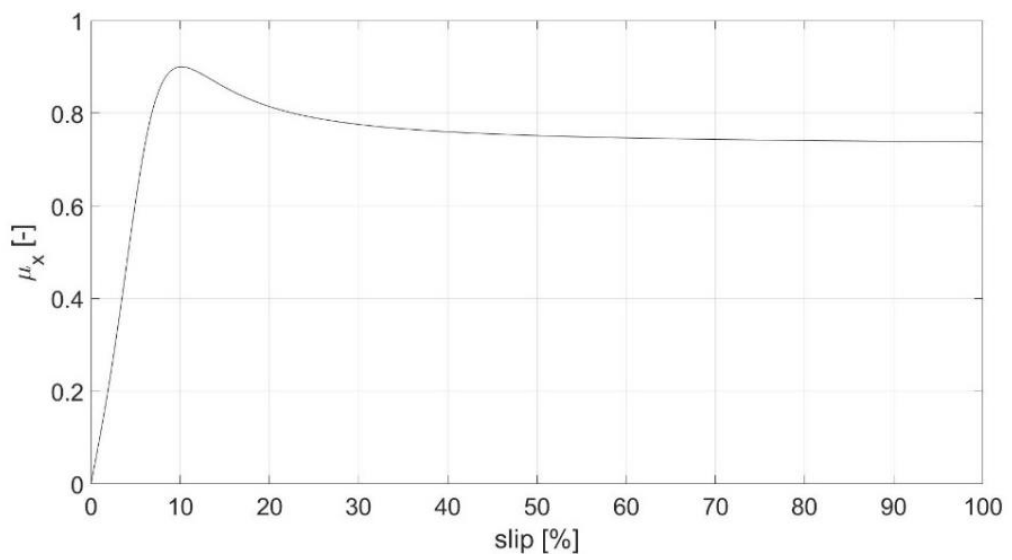

Figure 6

The graph of the Pacejka formula applying values $c_{1}=0.9, c_{2}=1.4, c_{3}=7.936, c_{4}=-10$

Air resistance force:

The magnitude of air resistance force is calculated as [3]:

$$
F_{\text {air }}=\frac{1}{2} \cdot C \cdot A \cdot \rho \cdot v_{s}^{2}
$$

where $C$ and $A$ are the coefficient of air resistance and maximum cross section area of the car normal to its moving direction, $\rho$ is the air density and $v_{S}$ is the speed of the car relative to air [4].

Rolling resistance forces and torques:

The magnitude of rolling resistance forces and torques in case of the front and back wheels of the vehicle are calculated as [9]:

$$
\begin{array}{ll}
F_{\text {rollf }}=\mu_{\text {rollf }} \cdot F_{n f}, & F_{\text {rollb }}=\mu_{\text {rollb }} \cdot F_{n b} \\
M_{\text {rollf }}=R \cdot F_{\text {rollf }}, & M_{\text {rollb }}=R \cdot F_{\text {rollb }}
\end{array}
$$

Where $\mu_{\text {rollf }}$ and $\mu_{\text {rollb }}$ are the coefficients of rolling resistance for the front and back wheels at given $F_{n f}$ and $F_{n b}$ normal forces exerted by the road on them. During intensive speed-up or braking the load on the back or front wheels 
increases significantly. We face the same situation applying a hevyer driver instead of a lighter one. Because of that the dependence of rolling resistance coefficient on vertival load $\left(\mu_{\text {roll }}\left(F_{n}\right)\right)$ was taken into consideration in the simulation program applying lookup tables (Figure 9 and 11). On the other hand at 3 bar tyre pressure - which is the value regularly applied in a race situation - the dependence of rolling resistance coefficient on vehicle speed is negligible in the whole speed range of the car [17]. The procedure for the measurement of rolling resistance coefficient as a function of tyre pressure and normal (vertical) load is presented in references $[10,11]$ in details.

\section{Bearing resistance torques:}

On the basis of our simulations, it can be stated, that the contribution of bearing resistance torque to the simulation results - in the case of the front and rear shafts of the vehicle - is negligible compared to the other factors. Additionally, taking it into consideration the running time of the simulation program increases significantly. Thus we neglected this factor. However, at the shaft of the rotor of the electric motor the bearing resistance and brush friction torques can not be neglected, thus we built it into our simulation program in the form of a look-up table $\left(\mathrm{M}_{\text {res }}\right.$, Figure 8$)$.

\section{The Simulation Program}

On the basis of our vehicle model we developed a simulation program in Matlab which is able to calculate the vehicle dynamics functions of a vehicle from its technical data. The program's block diagram is shown in Figure 7. [4]

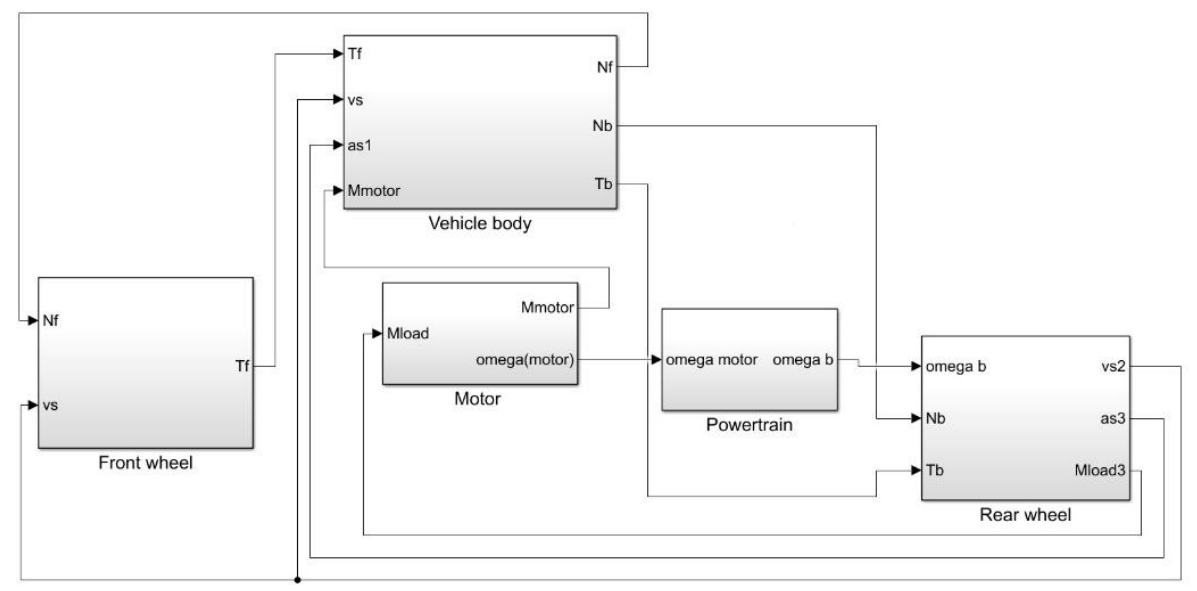

Figure 7

The block diagram of the simulation program in MATLAB Simulink 
The simulation program is built up of five modules in accordance with our dynamics model. The modules are:

- $\quad$ vehicle body

- front wheels and connected rotating machine parts

- $\quad$ back wheels and connected rotating machine parts

- motor

- powertrain

In the following we describe the structure and operation of the above modules in detail.

In references $[12,13,14,15,16]$ other examples for vehicle dynamics simulation programs are presented.

\subsection{The Motor}

The simulation module for the applyed series wound DC motor [8] is presented in Figure 8 .

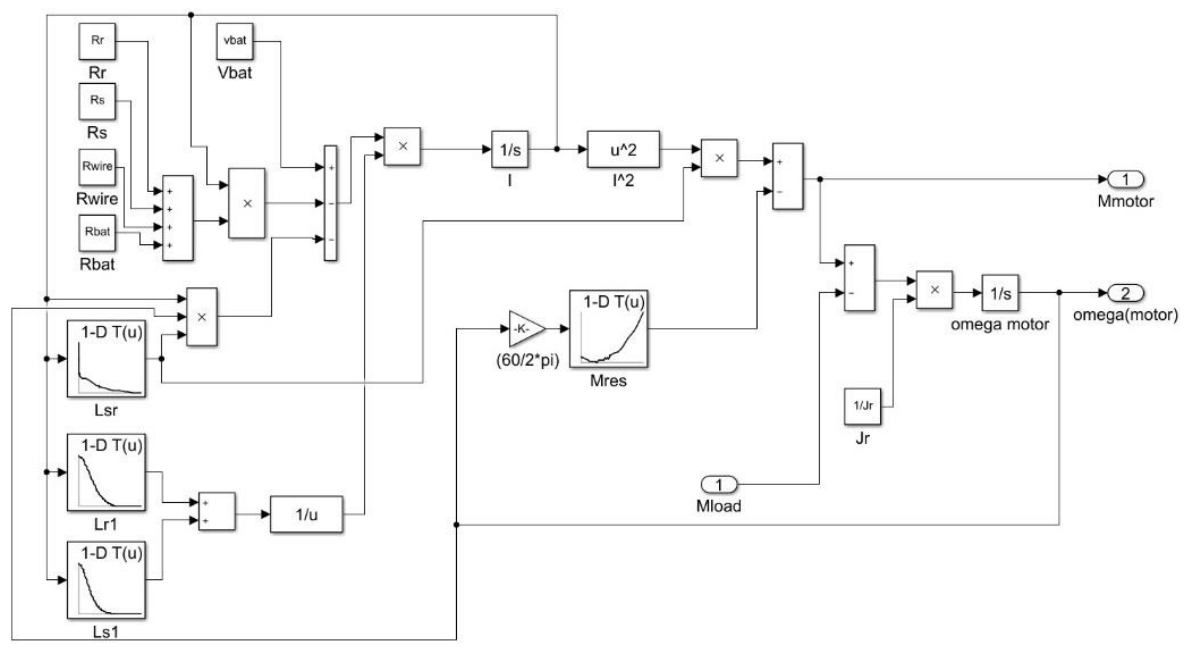

Figure 8

The motor simulation program module

The self and mutual dynamic inductances - together with the resistance torque of the shaft of the motor - are given as look-up tables in the program module. All the other parameters are given as constants. The program module is based on equations X and XII in Section 3. A more detailed description of the motor simulation program module - together with the description of the measurement process of the different input characteristics - can be found in reference [8]. 
In references $[17,18,19]$ other examples for the modeling of a series wound DC motor are presented.

\subsection{Front Wheels and Connected Rotating Machine Parts}

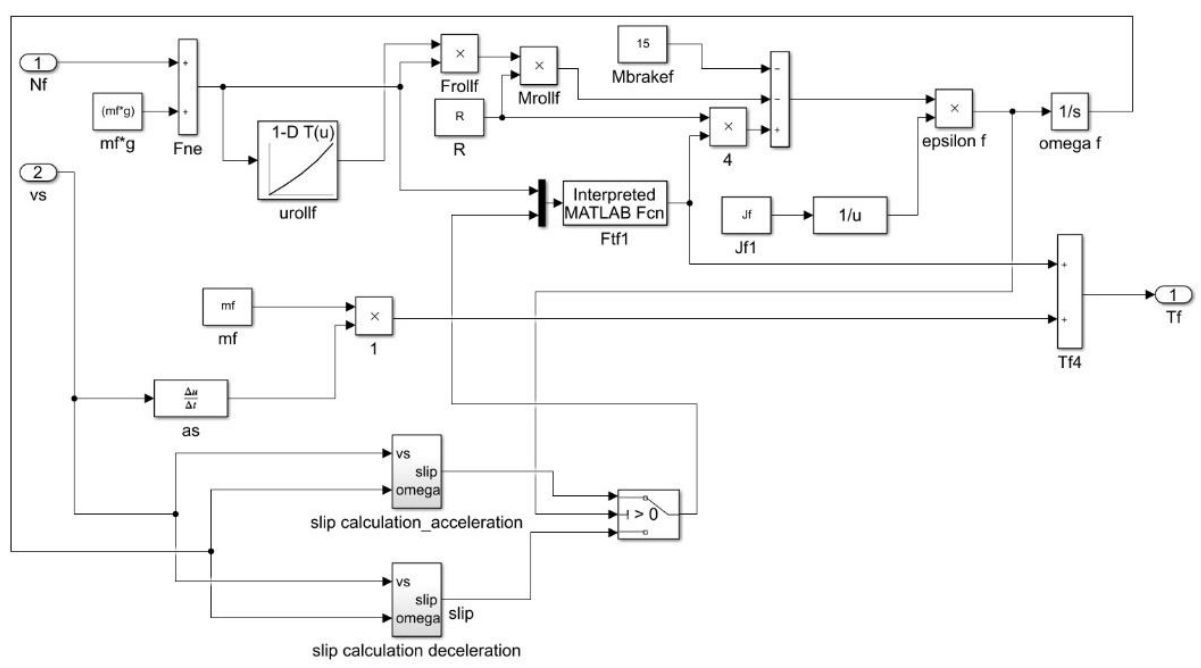

Figure 9

Simulation program module describing the front wheels and connected rotating machine parts

The program module - describing the front wheels together with the connected rotating machine parts - calculates the load on the front shaft in tangential direction $\left(\mathrm{T}_{\mathrm{f}}\right)$ from the load on it in normal direction $\left(\mathrm{N}_{\mathrm{f}}\right)$ and also from the velocity of the car $\left(\mathrm{v}_{\mathrm{s}}\right)$ on the basis of equations I, II and III (section 3.1). Parameters $\mathrm{N}_{\mathrm{f}}$ and $\mathrm{v}_{\mathrm{s}}$ are calculated by the program modules describing the vehicle body and back wheels respectively (Figures 14 and 10). The module calculates the angular velocity (omega(f)) of the front wheels independent of vehicle velocity $\left(\mathrm{v}_{\mathrm{s}}\right)$, and then the slip of the tyres from omega(f) and $\mathrm{v}_{\mathrm{s}}$ in case of acceleration and deceleration applying different formulas. 


\subsection{Back Wheels and Connected Rotating Machine Parts}

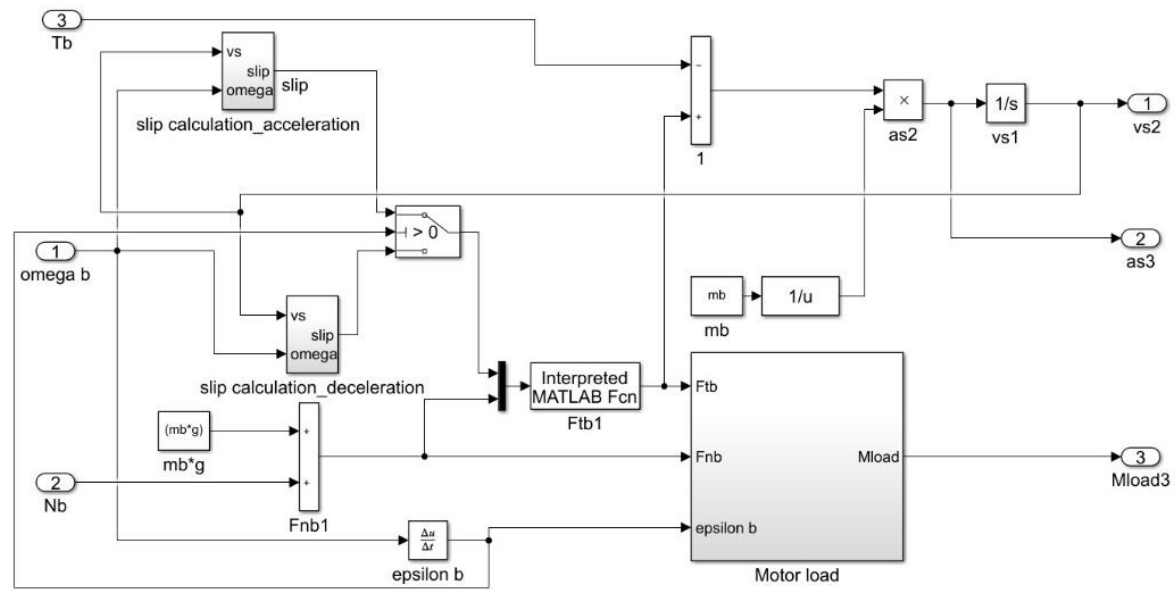

Figure 10

Simulation program module describing the back wheels and connected rotating machine parts

The program module - describing the back wheels with the rotating machine parts connected to them - calculates the load on the motor $\left(\mathrm{M}_{\text {load }}\right)$ together with the acceleration $\left(\mathrm{a}_{\mathrm{s}}\right)$ and velocity $\left(\mathrm{v}_{\mathrm{s}}\right)$ of the vehicle from the load on the back shaft in tangential $\left(\mathrm{T}_{\mathrm{b}}\right)$ and normal $\left(\mathrm{N}_{\mathrm{b}}\right)$ direction and also from the angular velocity of the back wheels (omega(b)) on the basis of equations IV, V and VI (Section 3.1).

Inside the module, there are „sub-modules” for the calculation of the load on the motor $\left(\mathrm{M}_{\text {load }}\right.$, Figure 11) and tyre slip in case of acceleration (Figure 12) and deceleration (Figure 13). The load on the motor is calculated from the forces exerted by the road on the back wheels in tangential $\left(\mathrm{F}_{\mathrm{tb}}\right)$ and normal $\left(\mathrm{F}_{\mathrm{nb}}\right)$ direction and also from the angular acceleration of the wheels $\left(\varepsilon_{\mathrm{b}}\right)$.

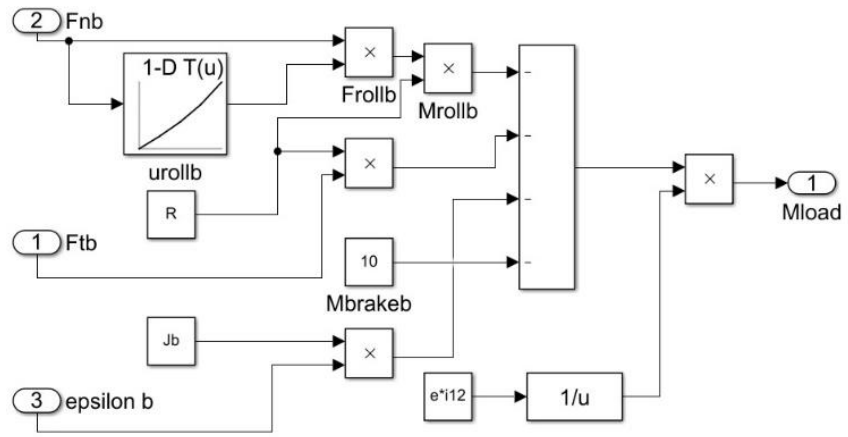

Figure 11

Program module for the calculation of the load on the motor 


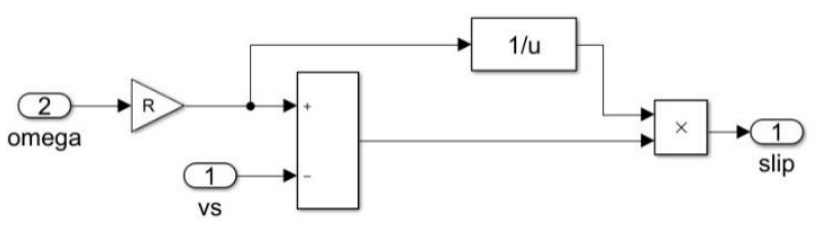

Figure 12

Program module for the calculation of tyre slip during acceleration

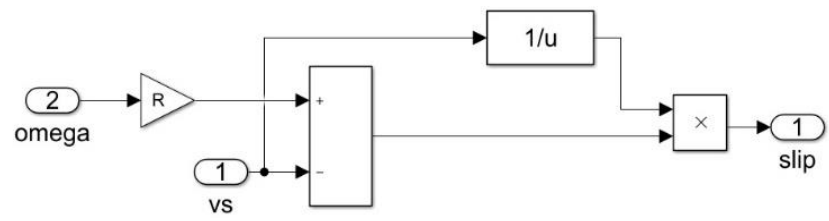

Figure 13

Program module for the calculation of tyre slip during deceleration

\subsection{Vehicle Body}

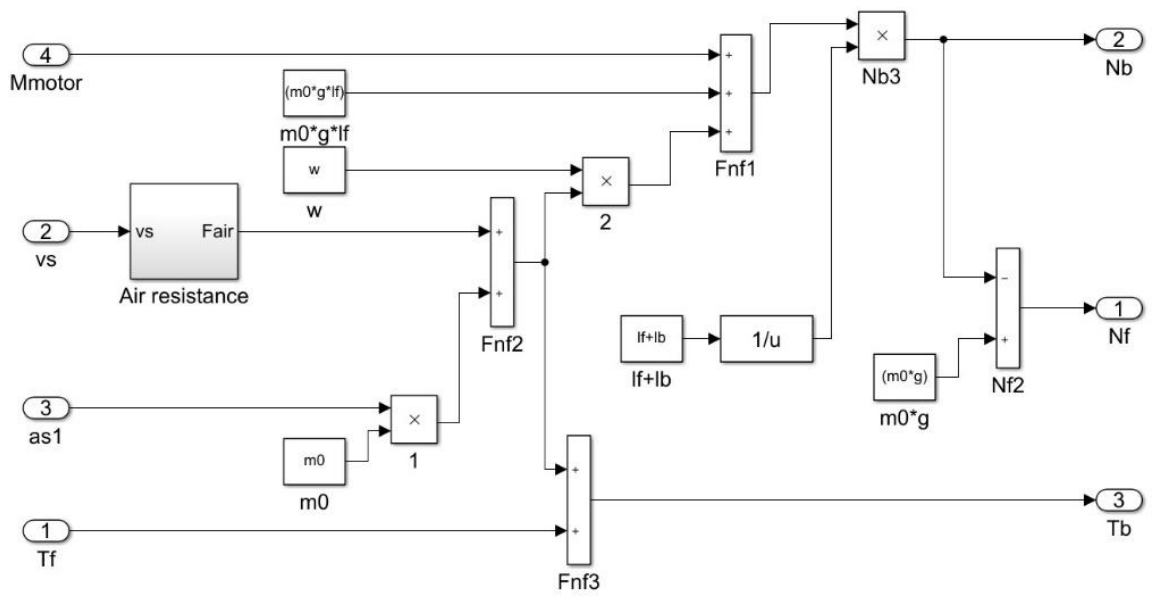

Figure 14

Program module for the description of vehicle body

The program module - describing the vehicle body - calculates the load on the back shaft in normal and tangential direction $\left(\mathrm{N}_{\mathrm{b}}, \mathrm{T}_{\mathrm{b}}\right)$ and also the one on the front shaft in normal direction $\left(\mathrm{N}_{\mathrm{f}}\right)$ from the torque that the motor exerts on the vehicle body $\left(\mathrm{M}_{\text {motor }}\right)$ and from the velocity $\left(\mathrm{v}_{\mathrm{s}}\right)$ and acceleration $\left(\mathrm{a}_{\mathrm{s}}\right)$ of the vehicle, and also from the load on the front shaft in the tangential direction $\left(\mathrm{T}_{\mathrm{f}}\right)$ on the basis of equations VII. VIII. and IX. (section 3.1). The load on the back shaft in normal direction is calculated by the formula 


$$
\mathrm{N}_{\mathrm{b}}=\frac{\left(\mathrm{T}_{\mathrm{b}}-\mathrm{T}_{\mathrm{f}}\right) \cdot \mathrm{w}+\mathrm{m}_{0} \cdot \mathrm{g} \cdot \mathrm{l}_{\mathrm{f}}+\mathrm{M}_{\text {motor }}}{\mathrm{l}_{\mathrm{b}}+\mathrm{l}_{\mathrm{f}}}
$$

which is derived from equations VIII. and IX. Inside the module, there is a "submodule" for the calculation of the magnitude of air resistance force (Figure 15).

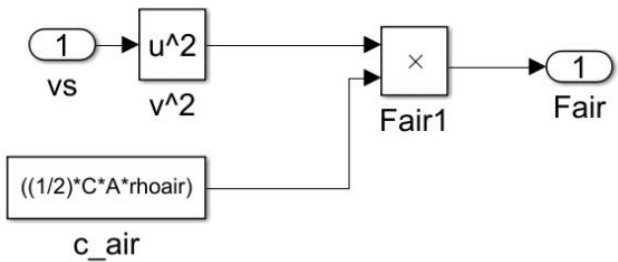

Figure 15

Program module for the calculation of air resistance force

\subsection{Powertrain}

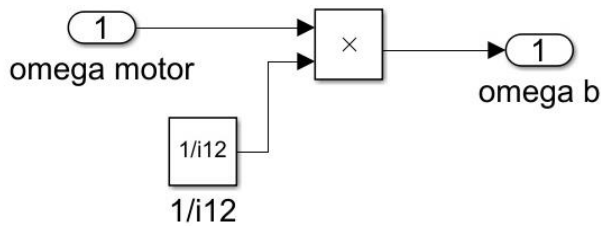

Figure 16

Program module for the description of the power train

The module calculates the angular velocity of the back wheel (omega(b)) from the angular velocity of the motor (omega(motor)) and the gear ratio $\left(i_{12}\right)$ of the chain drive.

\section{Output Dynamics Functions of the Program}

The program generates the following quantities as a function of time:

- The acceleration, velocity and covered distance of the vehicle

- The angular velocity and acceleration of the front and back wheels

- The forces the road exerts on the tyres in tangential and normal direction

- Front and back shafts loading in tangential and normal direction

- Rolling resistance torques

- $\quad$ Air resistance force 
- $\quad$ Tyre slip

- The intensity of the current flowing through the motor

- The torque and angular speed of the motor

It is important to emphasise that the simulation program stops with an error message if we give zero initial values in the integrators, which are: calculate the angular speed of the motor and the velocity of the car in the "Motor" and "Rear wheel" program modules. So small initial values have to be given to these quantities.

Figure 17 shows the (tractive) force exerted by the road on the back wheels in tangential direction $\left(\mathrm{F}_{\mathrm{tb}}\right)$ vs. time applying different gear ratios in the chain drive. At gear ratio 8 a sharp peak appears on the graph of the tractive force-time function. It is happening because meanwhile, the car is starting, the driven wheels are spinning up, and then - with increasing vehicle speed - the wheels stick to the road, which results in the sharp increase of the tactive force. The values of all the other parameters are the same in the presented three cases. [4]

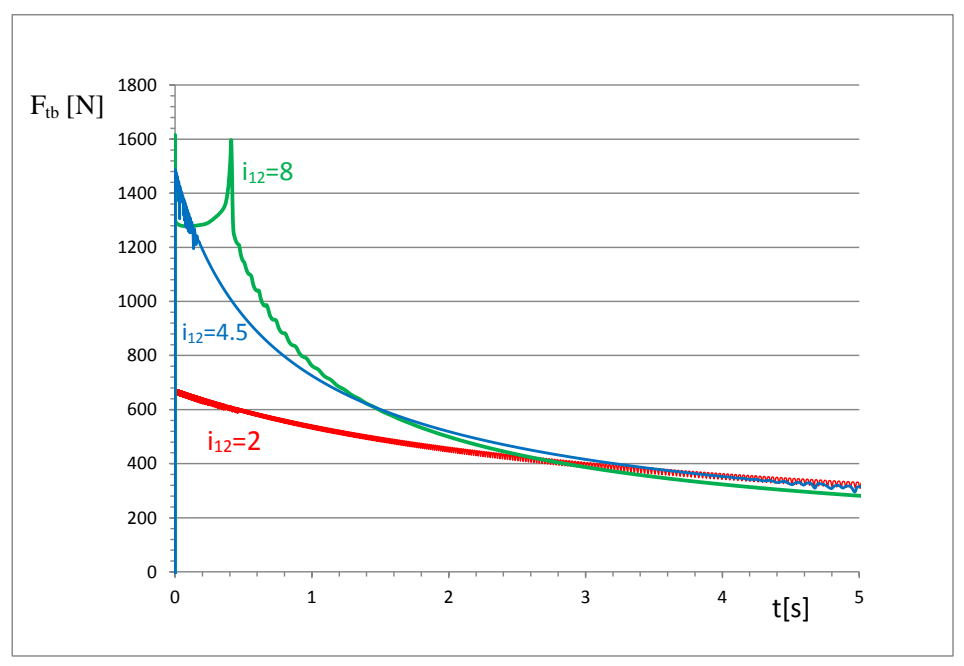

Figure 17

Tractive force on the back wheels vs. time [4]

Figure 18 shows the velocity vs. time functions of the car applying the same gear ratios as the ones in Figure 17. 


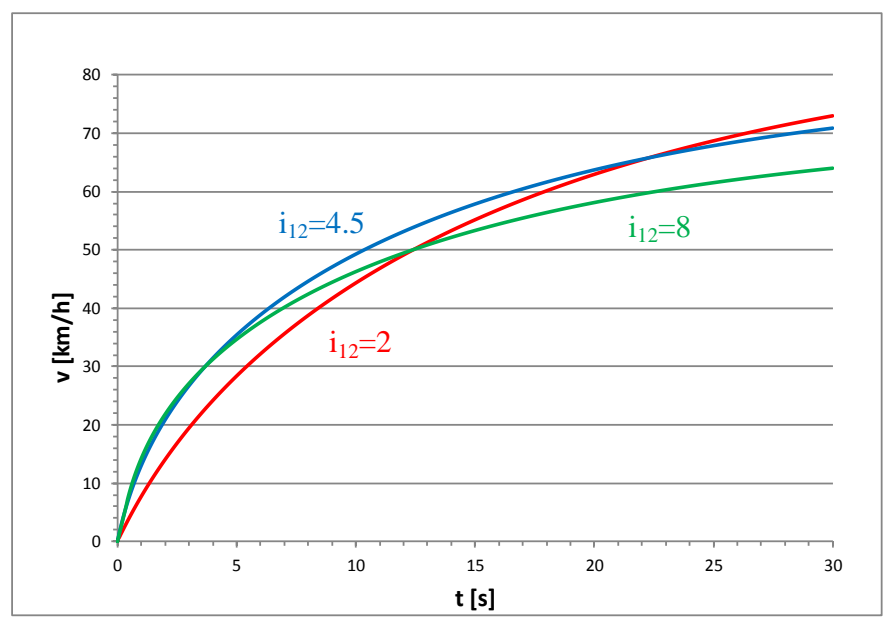

Figure 18

Velocity vs. time functions of the car applying different gear ratios [4]

Figure 19 presents the forces exerted by the road on the front and back wheels of the car in normal direction vs. time.

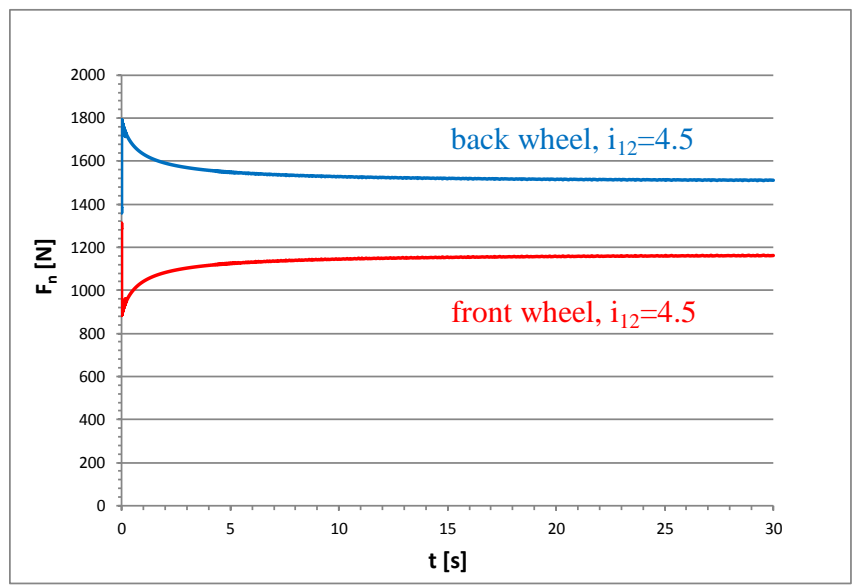

Figure 19

Forces exerted by the road on the front and back wheels of the car in normal direction vs. time [4]

Figure 20 presents the simulated velocity vs. time function of the car in case of $5 \mathrm{~s}$ acceleration and consequently that 5 s deceleration. 


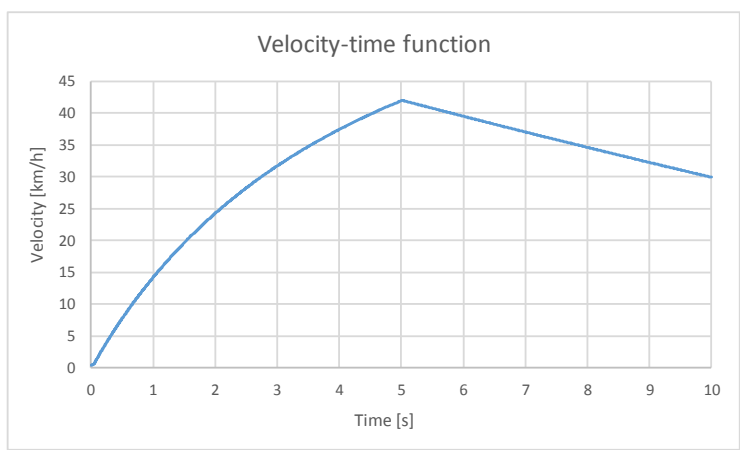

Figure 20

Velocity-time function of the car during during acceleration and braking

The supply voltage and braking torque belonging to the above simulation are presented in Figure 21.

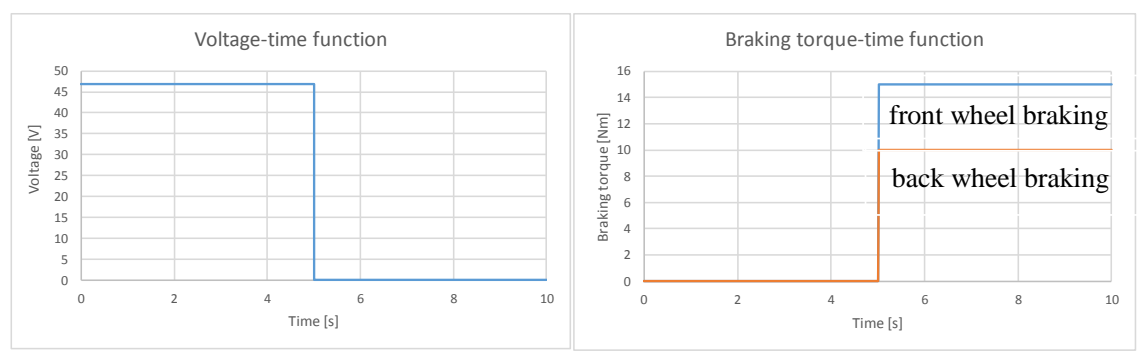

Figure 21

Supply voltage and braking torque as a function of time

\section{Conclusions}

A vehicle dynamic simulation program has been developed which is capable of the complete simulation of the motion of a vehicle on a linear track. The program has a modular structure, so the different construction parts (motor, vehicle body, drive train, front and back wheels and connected rotating machine parts) are modeled and simulated in separate program modules. The program takes into account all the factors which have a significant effect on the motion of the vehicle and can calculate all its vehicle dynamic functions.

In the recent work, the program was applied for the simulation of the motion of a prototype race car driven by a serious wound DC motor. The calculated dynamic functions give a good approximation of the real ones, but for the precise quantitative verification of the program, we intend to measure the values of all the missing input technical data, and then to perform precise telemetry measurements on the car in the near future. 


\section{Acknowledgement}

"The research was financed by the Thematic Excellence Programme of the Ministry for Innovation and Technology in Hungary (ED_18-1-2019-0028), within the framework of the (Automotive Industry) thematic programme of the University of Debrecen."

\section{References}

[1] Hans B. PACEJKA, Igo BESSELINK: Tire and Vehicle Dynamics (Thirdedition) - Published by Elseiver Ltd. (2012) ISBN 978-0-08-0970165

[2] Jörsen REIMPELL, Jürgen W. BETZLER, BÁRI Gergő, HANKOVSZKI Zoltán, KÁDÁR Lehel, LÉVAI Zoltán, NAGYSZOKOLYAI Iván: Gépjármüfutóművek I. (2012) ISBN 978-963-279-606-2

[3] Bernd HEISSING, Metin ERSOY: Chassic Handbook (2011) ISBN 978-38348-0994-0

[4] SZIKI Gusztáv Áron, HAJDU Sándor, SZÁNTÓ Attila: Vehicle dynamics modelling of an electric driven race car, Proceedings of the $3^{\text {rd }}$ International Scientific Conference on Advances in Mechanical Engineering, ISBN 978963-473-917-3, 2015

[5] KOST, F. (2014) Basic principles of vehicle dynamics. Brakes, Brake Control and Driver Assistance Systems, 12-27, doi:10.1007/978-3-65803978-3_2

[6] Bengt JACOBSON et al: Vehicle Dynamics. Department of Applied Mechanics, Chalmers University of Technology. 2016

[7] Reza N. JAZAR: Vehicle Dynamics: Theory and Application. Springer. 2008. ISBN: 978-0-387-74243-4

[8] SZIKI Gusztáv Áron; SARVAJCZ Kornél; KISS János; GÁL Tibor; SZÁNTÓ Attila; GÁBORA András; HUSI Géza: Experimental investigation of a series wound dc motor for modeling purpose in electric vehicles and mechatronics systems. In: MEASUREMENT (ISSN: 02632241) 109: pp. 111-118 (2017) IF: 1.742

[9] Dr. ILOSVAI Lajos Prof. Emeritus (2013) Jármüdinamika

[10] F. GRAPPE, R. CANDAU, B. BARBIER, M. D. HOFFMAN, A. BELLI, J.-D. ROUILLON: Infuence of tyre pressure and vertical load on coefficient of rolling resistance and simulated cycling performance, ERGONOMICS, 1999, VOL. 10, 1361-1371

[11] SZESZÁK B., SÜTŐ T., Nagyné KONDOR R., SZÍKI G., JUHÁSZ G.: Analysis of the Rolling Resistance of Pneumobils for Vehicle Dynamics Modelling Purpose. Proceedings of the $2^{\text {nd }}$ Agria Conference on Innovative 
Pneumatic Vehicles ACIPV 2018 / ed. Pokorádi László, pp. 17-20, ISBN 978-963-449-089-0

[12] József POLÁK and István LAKATOS. Examination of drive line mathematical model. Machine design 8(1):33-36, 2016

[13] József POLÁK and István LAKATOS. Efficiency optimization of electric permanent magnet motor driven vehicle. Machine design 7(1):11-14, 2015

[14] SHAKOURI, P., LAILA, D. S., ORDYS, A., \& ASKARI, M. (2010) Longitudinal vehicle dynamics using Simulink/Matlab. UKACC International Conference on Control 2010, doi:10.1049/ic.2010.0410

[15] SZAKÁCS T.: Pneumatic modelling of a pneumobil. In: Pokorádi, László (szerk.) Proceedings of the $2^{\text {nd }}$ Agria Conference on Innovative Pneumatic Vehicles ACIPV 2018 Eger, Magyarország : Óbudai Egyetem, (2018) pp. 25-30, $6 \mathrm{p}$.

[16] SZAKÁCS T.: Modelling and Validation of a Pneumobil. In: Pokorádi, László (szerk.) Proceedings of the $3^{\text {rd }}$ Agria Conference on Innovative Pneumatic Vehicles - ACIPV 2019 Eger, Magyarország : Óbudai Egyetem Mechatronikai és Jármütechnikai Intézet (2019) pp. 31-35, 5 p.

[17] Farhan A. Salem: Dynamic Modeling, Simulation and Control of Electric Machines for Mechatronics Applications. International Journal of Control, Automation and Systems Vol. 1, No. 2, April 2013 ISSN 2165-8277 (Print) ISSN 2165-8285 (Online)

[18] Zeina BITARA, Samih AL JABIA, Imad KHAMISB (2014): Modeling and Simulation of Series DC Motors in Electric Car, The International Conference on Technologies and Materials for Renewable Energy, Environment and Sustainability, TMREES14, Energy Procedia 50 (2014) $460-470$

[19] P. ZÁSKALICKÝ (2006): Modelling of a serial wound DC motor supplied by a semi controlled rectifier, Advances in Electrical and Electronic Engineering (AEEE) Vol. 5 (2006) 110-113 